\title{
De-escalation as part of a global strategy of empiric antibiotherapy management. A retrospective study in a medico-surgical intensive care unit
}

\author{
Jérôme Morel ${ }^{1 *}$, Julie Casoetto ${ }^{1}$, Richard Jospé ${ }^{1}$, Gérald Aubert ${ }^{2}$, Raphael Terrana ${ }^{1}$, Alain Dumont ${ }^{1}$, Serge Molliex',
} Christian Auboyer ${ }^{1}$

\begin{abstract}
Introduction: Most data on de-escalation of empirical antimicrobial therapy has focused on ventilator-associated pneumonia. In this retrospective monocentric study, we evaluated de-escalation as part of a global strategy of empiric antibiotherapy management irrespective of the location and the severity of the infection. The goal of this trial was to assess the application of a de-escalation strategy and the impact in terms of re-escalation, recurrent infection and to identify variables associated with de-escalation.

Methods: All consecutive patients treated with empiric antibiotic therapy and hospitalized in the intensive care unit for at least 72 hours within a period of 16 months were included. We compared the characteristics and outcome of patients who have experienced de-escalation therapy with those who have not.

Results: A total of 116 patients were studied corresponding to 133 infections. Antibiotic therapy was de-escalated in 60 cases (45\%). De-escalation, primarily accomplished by a reduction in the number of antibiotics used, was observed in 52\% of severe sepsis or septic shock patients. Adequate empiric antibiotic and use of aminoglycoside were independently linked with de-escalation. De-escalation therapy was associated with a significant reduction of recurrent infection ( $19 \%$ vs 5\% $P=0.01$ ). Mortality was not changed by de-escalation.
\end{abstract}

Conclusions: As part of a global management of empiric antibiotherapy in an intensive care unit, de-escalation might be safe and feasible in a large proportion of patients.

\section{Introduction}

The emergence of multidrug-resistant (MDR) pathogens is a major public health challenge and is directly correlated with over administration of antibiotics [1]. Controlling their use is thus a major objective of health. Responsible for more than one third of hospital admissions, infectious diseases are common in intensive care units [2]. Septic shock is present in $10 \%$ of intensive care unit (ICU) patients with a mortality rate of nearly $60 \%$ [3]. Early and adequate introduction of antibiotics improve survival in severe sepsis and septic shock

\footnotetext{
* Correspondence: jerome.morel@chu-st-etienne.fr

'Department of Anaesthesiology and Intensive Care Medicine, Centre Hospitalier Universitaire, Avenue A Raymond, Saint Etienne, 42055, France Full list of author information is available at the end of the article
}

patients [4-7]. Therefore, therapy such as broad-spectrum antibiotics and/or a combination of antibiotics must be started empirically. Guidelines recommend that physicians first combine broad-spectrum antibiotics followed by a reappraisal of the therapy as soon as bacteriological data and susceptibility tests are available in order to eventually reduce the number and the spectrum of the antibiotics $[8,9]$.

This therapeutic strategy called de-escalation is particularly pertinent in case of serious infection [10-18]. Its feasibility is quite variable across centers with figures varying from $10 \%$ to $90 \%$ of cases $[18,19]$. The overwhelming majority of these studies were restricted to patients with ventilator associated pneumonia (VAP) [11-17]. However, empiric broad spectrum antibiotics
C Biomed Central 
are indicated in many others situations frequently encountered in an ICU $[20,21]$.

We retrospectively evaluated the practice of de-escalation occurring over consecutive infections during a period of 16 months in a 10-bed intensive care unit, irrespective of type and severity of infection. The goal of the study was to assess the application of a de-escalation strategy on empirical antibiotics management. We particularly analyzed the clinical impact of this attitude in terms of re-escalation, recurrent infection and mortality and identified bio-clinical variables associated with deescalation.

\section{Materials and methods}

\section{Study design and patients}

This retrospective observational study was conducted from January 2007 to April 2008 in a French teaching hospital. All consecutive patients admitted to the ICU (10 beds) and treated with empiric antibiotherapy have been included, irrespective of the origin and the severity of the suspected infection. Patients discharged from the ICU within 72 hours, patients with bone marrow aplasia, and patients admitted to the ICU already under antibiotherapy for more than 48 hours were excluded from the analysis. All the data have been reviewed and analyzed by three physicians involved in daily patient care. The study has been approved by the ethics committee of Saint Etienne University Teaching Hospital (number 20-2010) and informed consent was not required.

Antibiotic prescription was not protocolised in our unit. Empiric antibiotherapy was based on patients' characteristics, and the severity and location of the infection. The choice was made by the physician in charge of the patient according to our local ecology and pattern of resistance. After microbiological samples, broad spectrum antibiotics are usually prescribed in combination. Microbiologists are interviewed every morning to reassess this initial strategy. This reappraisal takes into account microbiological results, antibiotic susceptibility and also the clinical evolution of the patients. Every antibiotic change is systematically discussed with the staff at least three times a week. Tracheal secretions and urinary samples are collected twice a week for bacteriologic culture. In parallel, a specific search for MDR bacteria carriage is performed (nasal, throat, and rectum) at the admission and thereafter weekly.

\section{Definitions}

De-escalation therapy was defined as either a switch to a narrower spectrum agent or the reduction in the number of antibiotics or the early arrest of antibiotic treatment.

A switch to a narrower antibiotic spectrum was considered when an antibiotic with activity against non- fermenting Gram-negative bacilli (nfGNB) (imipenemcilastatin, piperacillin-tazobactam, ceftazidime or ciprofloxacin) was replaced by a molecule without nfGNB activity, an antibiotic with activity against meticillin resistant staphylococcus (MRS) was replaced by a molecule with an activity against methicillin sensible staphylococcus (MSS), or a third generation cephalosporin was replaced by a group A penicillin.

Reduction in the number of antibiotics was defined by the arrest of at least one antibiotic occurring before the fifth day of antibiotherapy.

Early arrest of antibiotics is defined as the early cessation of antibiotherapy (before the third day of treatment) either due to the absence of proven bacterial infection or due to the withholding of medical therapies.

Severe sepsis and septic shock were defined according to the classical criteria [22]. MDR bacteria were defined as methicillin-resistant Staphylococcus aureus and coagulase-negative staphylococci; Enterobacteria producing an extended-spectrum beta-lactamase or producing a cephalosporinase; and nfGNB resistant to piperacillintazobactam, ceftazidime, or imipenem-cilastatin or producing an extended-spectrum beta-lactamase (Pseudomonas aeruginosa and Acinetobacter baumanii).

\section{Data collections}

On admission the following variables were recorded: age, gender, Simplified Physiologic Score II (SAPS II), type of admission, MDR organisms. We also gathered information on the length of stay and on ICU mortality. Nosocomial infections were considered when they occurred after at least 48 hours of hospitalization. Immuno-compromised patients were defined as patients with an evolutive neoplasia or patients treated by immunosuppressive agents (corticoids for more than three months whatever the dose or chemotherapy). The diagnosis of ventilator associated pneumonia was established according to the French guidelines [23]: new infiltrates on chest radiograph, and at least one of the following criteria: body temperature $>38^{\circ} \mathrm{C}$, white blood cell count of $<4,000 / \mathrm{mm}^{3}$ or $>12,000 / \mathrm{mm}^{3}$, and at least one of the following criteria: new onset of bronchial purulent sputum, alteration of arterial oxygenation, evocative pulmonary auscultation. Microbiological documentation is strongly recommended in cases with the presence of at least one microorganism at the concentration $\geq 10^{4}$ Colony Forming Units $/ \mathrm{ml}(\mathrm{CFU} / \mathrm{ml})$ in the broncho-alveolar lavage sample or $\geq 10^{5} \mathrm{CFU} / \mathrm{ml}$ in the tracheal secretions sample. The choice of empiric antibiotherapy may be helped by the result of the last systematic bacteriological samples. Urinary tract infection is difficult to diagnose in anesthetized patients. The definition used was the presence of at least one microorganism at the concentration $\geq 10^{5} \mathrm{CFU} / \mathrm{ml}$ with symptoms and/or urinary catheter $[23,24]$. 
Empiric antibiotic treatment was deemed effective if at least one antibiotic molecule was active against bacteria responsible for the infection.

We defined re-escalation as the resumption of a broad spectrum treatment justified by a clinical worsening, not necessarily related to the initial infection, and a recurrent infection as the reappearance of an infection after the cessation of all antibiotic therapy.

\section{Statistical analysis}

Qualitative variables were compared with chi-square test or Fisher exact test. Quantitative variables were compared with Student $t$-test. Univariate regression analysis was used to assess factors associated with de-escalation. All variables with a $P$-value $<0.1$ determined by univariate regression model were entered into a multivariate logistic regression model. A $P$-value $<0.05$ was considered statistically significant. Statistical analysis was performed using SAS version 9 (SAS Institute Inc., Cary, NC, USA).

\section{Results}

Out of the 363 patients that have been hospitalized in our ICU over the 16-month study period, 116 met the criteria of inclusion, corresponding to 133 empiric antibiotic regimens. Because of infection recurrence, 15 patients received 2 antibiotic regimens and 1 patient, 3 antibiotics regimens.

De-escalation of empiric antibiotherapy was accomplished in 60 cases (45\%), with a mean delay of $3.5 \pm$ 0.7 days after their introduction. A decrease in the number of antibiotics was found in 19 cases (32\%), a reduction of the spectrum in 5 cases $(8 \%)$, and both approaches were found in 21 cases (35\%). Antibiotic therapy was arrested early in 15 cases (25\%): 6 pulmonary edema, 2 non-infectious interstitial pneumonia, 1 mycotic infection, 2 unknown etiologies, and 4 withholding medical therapies.

We analyzed two sub-groups of patients as a function of their de-escalation status: Group D corresponding to 60 empiric antibiotic regimens with de-escalation and Group ND corresponding to 73 empiric antibiotic regimens with no de-escalation.

Patients' admission characteristics are summarized in Table 1. No significant difference was noted between the two groups except a higher proportion of MDR bacteria carriage and less frequent primary diagnosis of infection at the admission for the patients of Group ND. Delay of empiric antibiotic introduction was not different between the two groups $(5 \pm 12$ days and $5 \pm 10$ days for Group D and Group ND, respectively). Severity and type of infection were similar between the two groups except for mediastinitis (Table 2).

De-escalation occurred in 20 non-documented infections (15 early withdrawal and 5 reductions in the
Table 1 Patients' characteristics at admission to intensive care unit. Comparison between groups $D$ and ND

\begin{tabular}{|c|c|c|c|c|}
\hline & & $\begin{array}{c}\text { Group D } \\
N=60\end{array}$ & $\begin{array}{c}\text { Group ND } \\
n=73\end{array}$ & $P$-value \\
\hline \multicolumn{2}{|l|}{ Age, years mean $\pm S D$} & $62 \pm 13$ & $60 \pm 17$ & 0.46 \\
\hline \multicolumn{2}{|l|}{ SAPS II, mean \pm SD } & $41 \pm 15$ & $40 \pm 16$ & 0.68 \\
\hline \multicolumn{2}{|c|}{ Immuno-compromised patients, n (\%) } & $17(28.3)$ & $15(20.5)$ & 0.29 \\
\hline \multicolumn{2}{|c|}{ MDR, n (\%) } & $1(1.6)$ & 7 (9.6) & 0.05 \\
\hline \multicolumn{2}{|c|}{ Admission for infectious diseases } & $27(45)$ & $16(22)$ & 0.004 \\
\hline & Surgery & $37(61.6)$ & $43(59)$ & \\
\hline \multirow[t]{2}{*}{ Type of admission, n (\%) } & Medicine & $21(35)$ & $20(27.4)$ & 0.10 \\
\hline & Trauma & $2(3.3)$ & $10(13.6)$ & \\
\hline \multicolumn{2}{|c|}{ Length of stay, days mean $\pm S D$} & $28 \pm 33$ & $24 \pm 23$ & 0.38 \\
\hline
\end{tabular}

MDR, multidrug resistant pathogens; SAPS II: Simplified Acute Physiology Score.

number of antibiotics). Microbiological details of documented infections are given in Table 3 and site by site in Table 4. The rate of antibiotic appropriateness was $43 \%$ for pulmonary infection (ventilator associated pneumonia and pneumonia), $80 \%$ for urinary tract infection, and $100 \%$ for the others sites. MDR bacteria and nfGNB were equally distributed between the two groups. An inadequate empiric broad-spectrum antibiotic therapy was more frequent in Group ND (27.5\% versus $7.7 \%$ $P=0.02)$ and involved a MDR bacteria in $50 \%$ of cases. More details on antibiotics used can be found in Additional file 1 . De-escalation was directly influenced by the

Table 2 Characteristics of patients and type of infection at the moment of empiric antibiotics prescription

\begin{tabular}{|c|c|c|c|c|}
\hline & & $\begin{array}{c}\text { Group D } \\
n=60\end{array}$ & $\begin{array}{c}\text { Group } \\
\text { ND } \\
n=73\end{array}$ & $P$-value \\
\hline \multicolumn{2}{|c|}{ Procalcitonine, mean $\pm \mathrm{SD}, \mu \mathrm{g} / \mathrm{l}$} & $7.8 \pm 15$ & $8.3 \pm 18.5$ & 0.87 \\
\hline \multicolumn{2}{|c|}{ Leukocyte count, mean \pm SD, mg/l } & $\begin{array}{l}13.6 \pm \\
7.3\end{array}$ & $12.4 \pm 6.1$ & 0.34 \\
\hline \multicolumn{2}{|c|}{ Nosocomial infection, n (\%) } & $54(90)$ & $62(85)$ & 0.38 \\
\hline & Sepsis & $21(35)$ & $35(48)$ & \\
\hline \multirow{2}{*}{$\begin{array}{l}\text { Severity of infection, } \\
\mathrm{n}(\%)\end{array}$} & Severe sepsis & $23(38.3)$ & $24(32.8)$ & 0.3 \\
\hline & Septic shock. & $16(26.6)$ & $14(19.2)$ & \\
\hline \multicolumn{5}{|c|}{ Type of infections, n (\%) } \\
\hline \multicolumn{2}{|c|}{ Ventilator-associated pneumonia } & $28(46.6)$ & $34(46.5)$ & 0.9 \\
\hline \multicolumn{2}{|c|}{ Pneumonia } & $13(21.6)$ & $24(32.8)$ & 0.15 \\
\hline \multicolumn{2}{|c|}{ Urinary tract infection } & $2(3.3)$ & $3(4.1)$ & 0.81 \\
\hline \multicolumn{2}{|c|}{ Catheter-related bacteriemia } & $1(1.6)$ & 0 & 0.28 \\
\hline \multicolumn{2}{|c|}{ Endocarditis } & $1(1.6)$ & 0 & 0.28 \\
\hline \multicolumn{2}{|l|}{ Mediastinitis } & $5(8.3)$ & 0 & 0.01 \\
\hline \multicolumn{2}{|l|}{ Peritonitis } & $6(10)$ & $7(9.6)$ & 0.97 \\
\hline \multicolumn{2}{|l|}{ Meningitis } & $1(1.6)$ & 0 & 0.28 \\
\hline \multicolumn{2}{|c|}{ Otorhinolaryngeal infection } & 0 & $1(1.4)$ & 0.34 \\
\hline \multicolumn{2}{|c|}{ Undetermined infection location } & $4(6.6)$ & $4(5.5)$ & 0.84 \\
\hline
\end{tabular}


Table 3 Microbiologic characteristics of infectious episodes. Comparison between groups D and ND

\begin{tabular}{|c|c|c|c|}
\hline & $\begin{array}{c}\text { Group D } \\
n=60\end{array}$ & $\begin{array}{c}\text { Group } \\
\text { ND } \\
n=73\end{array}$ & $P$-value \\
\hline Microbiological samples, n (\%) & $59(98)$ & $63(86)$ & 0.17 \\
\hline $\begin{array}{l}\text { Positive microbiological } \\
\text { documentation, } \mathrm{n}(\%)\end{array}$ & $40(66.6)$ & $39(53.4)$ & 0.23 \\
\hline $\begin{array}{l}\text { Inadequate empiric antibiotherapy, } \\
\text { n (\%) } \S\end{array}$ & $3(7.7 \%)$ & $11(27.5 \%)$ & 0.02 \\
\hline \multicolumn{4}{|l|}{ Bacteria related to infection, $\mathrm{n}(\%)$ : } \\
\hline Staphylococcus aureus & $11(18.3) *$ & $7(9.6) *$ & 0.18 \\
\hline CoNS & $5(8.3) \$$ & 0 & 0.02 \\
\hline Streptococci species & $3(5)$ & $8(11)$ & 0.47 \\
\hline Enterococci species & $2(3.3)$ & $2(2.7)$ & 0.89 \\
\hline Gram negative cocci & $2(3.3)$ & 0 & 0.14 \\
\hline Enterobacteria & $16(26.6)$ & $23(31.5)$ & 0.54 \\
\hline $\mathrm{nfGNB}$ & $4(6.6)$ & $5(6.8)$ & 0.9 \\
\hline Others gram negative bacilli & $7(11.6)$ & $5(6.8)$ & 0.14 \\
\hline Intracellular bacteria & 0 & $1(1.3)$ & 0.34 \\
\hline $\begin{array}{l}\text { MDR responsible for the infection, } \\
\mathrm{n}(\%)\end{array}$ & $6(10)$ & 7 (9.6) & 0.97 \\
\hline Polymicrobial infections, n (\%) & $13(21.6)$ & $13(17.8)$ & 0.81 \\
\hline Infection recurrence, n (\%) & $3(5)$ & $14(19)$ & 0.01 \\
\hline MDR during the ICU stay, n (\%) & $6(10)$ & $14(19.1)$ & 0.1 \\
\hline
\end{tabular}

$\S$ Among documented infection; *1 methicillin resistant; \$ 2 methicillin resistant.

CoNS, coagulase negative staphylococcus; MDR, multidrug resistant pathogen; nfGNB, non fermenting Gram-negative bacilli.

number of empiric antibiotics used (Table 5). Only MRS-active antibiotics and aminoglycoside were associated with a more frequent de-escalation (Table 5). De-escalation therapy did not modify the duration of antibiotic therapy, $9.5 \pm 6$ days versus $10 \pm 5$ days for Group D and Group ND, respectively.

A re-escalation of antibiotics occurred in four patients, on average $3.75 \pm 1.5$ days after de-escalation and was due in half of the cases to MDR $P$. aeruginosa

Table 4 Site of infection among documented infections. Comparison between groups D and ND

\begin{tabular}{|c|c|c|c|}
\hline Site of infection & $\begin{array}{c}\text { Group } \\
\text { D } \\
n=40\end{array}$ & $\begin{array}{c}\text { Group } \\
\text { ND } \\
n=39\end{array}$ & $P$-value \\
\hline $\begin{array}{l}\text { Ventilator-associated pneumonia, n } \\
(\%)\end{array}$ & $19(47.5)$ & $23(59)$ & 0.07 \\
\hline Pneumonia, n (\%) & $11(27.5)$ & $12(31)$ & 0.25 \\
\hline Urinary tract infection, n (\%) & $2(5)$ & $3(7.7)$ & 0.32 \\
\hline Catheter-related bacteriemia, n (\%) & $1(2.5)$ & 0 & \\
\hline Endocarditis, n (\%) & $1(2.5)$ & 0 & \\
\hline Mediastinitis, n (\%) & $3(7.5)$ & 0 & \\
\hline Peritonitis, n (\%) & $3(7.5)$ & $1(2.6)$ & 0.4 \\
\hline Meningitis, n (\%) & 0 & 0 & \\
\hline Otorhinolaryngeal infection, n (\%) & 0 & 0 & \\
\hline
\end{tabular}

strain. Recurrent infections were more common in Group ND (19\% versus 5\%, $P=0.01)$, with $50 \%$ caused by MDR bacteria (Table 3). Mortality was not different between the two groups $18.3 \%$ vs $24.6 \%$ for Group D and Group ND, respectively. In multivariate analysis, only aminoglycosides and adequate antibiotic therapy were independent factors associated with de-escalation (Table 6). MDR pathogens at admission and monotherapy were found not to be associated with deescalation (Table 6).

\section{Discussion}

In this retrospective study, de-escalation, as a global management of antibiotherapy in the ICU, occurred in $45 \%$ of the cases. De-escalation was possible irrespective of the severity of the infection, and more frequently translated into a reduction of the number of antibiotics rather than a reduction of the spectrum. Although the study was not powered for clinical outcomes, de-escalation seems to be safe with no excess of mortality and might even allow a reduction in recurrent infections.

Many variables play a role in de-escalation and may explain the large variation of incidence found in the literature; $6.1 \%$ [19] to $98 \%$ [18].

First of all there is no consensual definition for deescalation. De-escalation therapy was defined as either a switch to a narrower spectrum agent, or the reduction in the number of antibiotics, or the early arrest of antibiotic treatment $[10,11,16,17]$. By focusing on two factors known to facilitate MDR emergence, namely the broad spectrum antibiotics and the number of antibiotics associated, this definition is probably the most relevant from a microbiological standpoint $[25,26]$.

An overwhelming majority of the studies published on de-escalation so far has focused on VAP [10-16]. VAP is traditionally the main reason for antibiotic administration in the ICU, and as such, represents in our study a substantial proportion of infections. Nearly $40 \%$ of empiric antibiotherapies are administered for an infection located other than in the respiratory tract [27], illustrating our objective to assess de-escalation as part of a global antibiotherapy management for non-selected infections. In this context, we show that de-escalation is feasible in many other situations such as mediastinitis or peritonitis, situations which like VAP also require broad spectrum antibiotics.

We confirm that de-escalation is achieved more frequently by reducing the number of drugs rather than by reducing the spectrum of antibiotic therapy $[10,15,16]$. Monotherapy is accordingly independently associated with the absence of de-escalation. Aminoglycosides were the antibiotics most frequently de-escalated. The risk of nephrotoxicity and the necessity to adapt their posology are probably one explanation. 
Table 5 Empirical antibiotic treatment. Comparison between groups D and ND

\begin{tabular}{lccc}
\hline & Group D & Group ND & P-value \\
& $\boldsymbol{n}=\mathbf{6 0}$ & $\mathbf{7 3}$ & 0 \\
\hline Antibiotic with activity against MSS, $\mathrm{n}(\%)$ & $2(3.3)$ & $12(16.4)$ & 0.12 \\
Antibiotic with activity against MRS, $\mathrm{n}(\%)$ & $21(35)$ & $50(68.5)$ & 0.01 \\
B-lactam antibiotic with no activity against nfGNB, $\mathrm{n}(\%)$ & $36(60)$ & $27(37)$ & 0.31 \\
B-lactam antibiotic with activity against nfGNB, $\mathrm{n}(\%)$ & $26(43.3)$ & $5(11)$ & 0.41 \\
Quinolone (except ciprofloxacin), $\mathrm{n}(\%)$ & $2(8.3)$ & $3(4.1)$ & $<.53$ \\
Aminoglycoside, $\mathrm{n}(\%)$ & $20(32.3)$ & $44(60.3)$ & $<0.0001$ \\
Monotherapy, $\mathrm{n}(\%)$ & $14(23.3)$ & $4(5.4)$ & $<0.001$ \\
More than two antibiotics, $\mathrm{n}(\%)$ & $19(31.7)$ & 0.002 \\
\hline
\end{tabular}

MRS, methicillin-resistant staphylococcus; MSS, methicillin-sensible staphylococcus; nfGNB, non fermenting Gram-negative bacilli.

Absence of positive microbial documentation did not apparently influence our strategy of de-escalation. Of note, $70 \%$ of cases without microbial documentation were obviously non-bacterial disease and thus the decision to de-escalate was easy. De-escalation is, however, more problematic when the clinician has a strong suspicion of bacterial infection with no positive microbial documentation $[11,15]$. This concept of de-escalation in patients with no microbial documentation is not widely accepted and is still a matter of discussion. Early clinical evolution under antibiotics may help the clinician with this choice [28]. In the case of documented infection, there is no consensus as to whether de-escalation should extend to infections with MDR pathogens. Although deescalation seems to be possible when such pathogens are directly responsible for the infection $[10,16]$, this strategy remains restricted to non-MDR pathogeninduced infections $[11,13]$. In two successive works Rello et al. showed an increase in de-escalation rate (6.1\% vs $31.4 \%)$, while the incidence of $P$. aeruginosa decreased from $50 \%$ to $15 \%[11,19]$. De-escalation was only done in $2.7 \%$ of infections with MDR pathogens compared with $49.3 \%$ in those with other agents [11]. Whether the decrease of $P$. aeruginosa incidence is the cause or the consequence of the increase in de-escalation strategy is not clear. On the other hand, Leone et al. reported a de-escalation rate of $54 \%$ for VAP due to $P$. aeruginosa, $A$. baumanii and methicillin resistant S. aureus as compared to $39 \%$ for VAP due to other bacteria [10]. In this study incidence of MDR agents

Table 6 Multivariate logistic regression analysis to assess factors associated with de-escalation therapy

\begin{tabular}{ccc}
\hline & OR $(\mathbf{9 5} \%$ IC) & P-value \\
\hline MDR at admission & $0.02(0.00 ; 0.36)$ & 0.008 \\
Aminoglycoside & $18.08(2.25 ; 145)$ & 0.006 \\
Monotherapy & $0.28(0.12 ; 0.63)$ & 0.002 \\
Adequate antibiotic therapy & $5.25(1 ; 27.4)$ & 0.049 \\
\hline
\end{tabular}

MDR, multidrug resistant pathogen was nearly $16 \%$. With less than $10 \%$ of MDR pathogen incidence, we are not powered to analyze the influence of MDR pathogen identification on our strategy of deescalation.

Consequences of de-escalation therapy on the emergence of bacterial resistance are difficult to analyze. We did not find a lower incidence of MDR acquisition in Group D (10\% vs $19.1 \%, P=0.10)$.

In our study, severity of the infection did not impact our decision to de-escalate. Among the patients with severe sepsis or in septic shock (near 60\% of our cohort), de-escalation was possible in $65 \%$ of the cases which is in agreement with what has been previously reported [17].

Interestingly, recurrent infections were increased in Group ND (19\% versus 5\%, $P=0.01)$. Singh et al. compared a de-escalation strategy (short course of empiric antibiotics therapy) to standard care. Antimicrobial resistance and/or superinfections were documented in $15 \%$ of the patients in the experimental group and in $35 \%$ of the patients in the control group [28]. A decrease in mortality rate and length of stay had sometimes been described with de-escalation $[10,13,15,16]$. The number of patients was not large enough to detect an impact of de-escalation on this outcome in this study. In our study, four re-escalations (6.6\%) occurred, which is comparable of Leone's study (6\%) [10]. We did not record a decrease in antibiotic duration in Group D.

The main limit of this study is its retrospective design. We aimed to get a comprehensive picture of our daily practice. While a prospective gathering of data would have probably influenced our attitude in favour of deescalation, it would be the clinical trial design of choice to answer the question of de-escalation efficiency. Moreover, delay in de-escalation might be considered long (3.5 \pm 0.7 days) with respect to the current guidelines (two to three days) [8], but maybe not in respect to clinical practice [10]. The study is not powered to detect an impact of de-escalation on MDR emergence, although this is one of the main aims of this strategy. 
The implementation of a de-escalation directed protocol for antibiotic management compared to a more liberal strategy with no de-escalation may answer this question.

\section{Conclusions}

As part of a global management of empiric antibiotherapy in an ICU, de-escalation might be safe and feasible in a large proportion of patients and infections. Deescalation is not realized in more than $50 \%$ of the antibiotherapy. Identification of the reasons that impair the decision towards de-escalation could eventually help to curb the clinician's reluctance to generalize this strategy.

\section{Key messages}

- De-escalation is feasible in many infections other than ventilator associated pneumonia.

- De-escalation is mostly accomplished by a reduction in the number of antibiotics used.

- Adequate empiric antibiotic and use of aminoglycosides were independently linked with de-escalation.

\section{Additional material}

Additional file 1: Supplementary material. Description of empirical antibiotics used and description of empirical antibiotics association among documented infections.

\begin{abstract}
Abbreviations
CFU/ml: Colony Forming Units/ml; MDR: multi-drug resistant; MRS: methicillin-resitant staphylococcus; MSS: methicillin-sensible staphylococcus; nfGNB: nonfermenting Gram negative bacilli; SAPS II: Simplified Physiologic Score II; VAP: ventilator-associated pneumonia
\end{abstract}

\section{Acknowledgements}

We thank all the nurses and doctors who contributed to this study. We also thank Professor C Marriat for reviewing this report and Doctor S Laporte for her help in statistic management.

\section{Author details}

${ }^{1}$ Department of Anaesthesiology and Intensive Care Medicine, Centre Hospitalier Universitaire, Avenue A Raymond, Saint Etienne, 42055, France. Department of Microbiology, Centre Hospitalier Universitaire, Avenue A Raymond, Saint Etienne, 42055, France.

\section{Authors' contributions}

$J M, J C$ and CA participated in the design of the study. GA carried out microbiological analysis. JM and SM performed the statistical analysis. JC, RJ and CA gathered and analyzed the data. JM, JC, SM and CA drafted the manuscript. All authors read and approved the final manuscript.

\section{Competing interests}

The authors declare that they have no competing interests.

Received: 31 August 2010 Revised: 17 September 2010

Accepted: 17 December 2010 Published: 17 December 2010

\section{References}

1. Kollef MH, Micek ST: Strategies to prevent antimicrobial resistance in the intensive care unit. Crit Care Med 2005, 33:1845-1853.

2. Alberti C, Brun-Buisson C, Chevret S, Antonelli M, Goodman SV, Martin C, Moreno R, Ochagavia AR, Palazzo M, Werdan K, Le Gall JR: Systemic inflammatory response and progression to severe sepsis in critically ill infected patients. Am J Respir Crit Care Med 2005, 171:461-468.

3. Annane D, Aegerter P, Jars-Guincestre MC, Guidet B: Current epidemiology of septic shock: the CUB-Rea Network. Am J Respir Crit Care Med 2003, 168:165-172

4. Kollef MH, Sherman G, Ward S, Fraser VJ: Inadequate antimicrobial treatment of infections: a risk factor for hospital mortality among critically ill patients. Chest 1999, 115:462-474.

5. Kumar A, Roberts D, Wood KE, Light B, Parrillo JE, Sharma S, Suppes R, Feinstein D, Zanotti S, Taiberg L, Gurka D, Kumar A, Cheang M: Duration of hypotension before initiation of effective antimicrobial therapy is the critical determinant of survival in human septic shock. Crit Care Med 2006, 34:1589-1596.

6. Larche J, Azoulay E, Fieux F, Mesnard L, Moreau D, Thiery G, Darmon M, Le Gall JR, Schlemmer B: Improved survival of critically ill cancer patients with septic shock. Intensive Care Med 2003, 29:1688-1695.

7. Torres A, Aznar R, Gatell JM, Jimenez P, Gonzalez J, Ferrer A, Celis R, Rodriguez-Roisin R: Incidence, risk, and prognosis factors of nosocomial pneumonia in mechanically ventilated patients. Am Rev Respir Dis 1990, 142:523-528.

8. Niederman MS: De-escalation therapy in ventilator-associated pneumonia. Curr Opin Crit Care 2006, 12:452-457.

9. Dellinger RP, Levy MM, Carlet JM, Bion J, Parker MM, Jaeschke R, Reinhart K, Angus DC, Brun-Buisson C, Beale R, Calandra T, Dhainaut JF, Gerlach H, Harvey M, Marini JJ, Marshall J, Ranieri M, Ramsay G, Sevransky J, Thompson BT, Townsend S, Vender JS, Zimmerman JL, Vincent JL: Surviving Sepsis Campaign: international guidelines for management of severe sepsis and septic shock: 2008. Crit Care Med 2008, 36:296-327.

10. Leone M, Garcin F, Bouvenot J, Boyadjev I, Visintini P, Albanese J, Martin C: Ventilator-associated pneumonia: breaking the vicious circle of antibiotic overuse. Crit Care Med 2007, 35:379-385, quizz 386.

11. Rello J, Vidaur L, Sandiumenge A, Rodriguez A, Gualis B, Boque C, Diaz E: De-escalation therapy in ventilator-associated pneumonia. Crit Care Med 2004, 32:2183-2190.

12. Soo Hoo GW, Wen YE, Nguyen TV, Goetz MB: Impact of clinical guidelines in the management of severe hospital-acquired pneumonia. Chest 2005, 128:2778-2787.

13. Alvarez-Lerma F, Alvarez B, Luque P, Ruiz F, Dominguez-Roldan JM, Quintana E, Sanz-Rodriguez C: Empiric broad-spectrum antibiotic therapy of nosocomial pneumonia in the intensive care unit: a prospective observational study. Crit Care 2006, 10:R78.

14. Hoffken G, Niederman MS: Nosocomial pneumonia: the importance of a de-escalating strategy for antibiotic treatment of pneumonia in the ICU. Chest 2002, 122:2183-2196.

15. Kollef MH, Morrow LE, Niederman MS, Leeper KV, Anzueto A, Benz-Scott L, Rodino FJ: Clinical characteristics and treatment patterns among patients with ventilator-associated pneumonia. Chest 2006, 129:1210-1218.

16. Giantsou E, Liratzopoulos N, Efraimidou E, Panopoulou M, Alepopoulou E, Kartali-Ktenidou S, Manolas K: De-escalation therapy rates are significantly higher by bronchoalveolar lavage than by tracheal aspirate. Intensive Care Med 2007, 33:1533-1540.

17. Leone M, Bourgoin A, Cambon S, Dubuc M, Albanese J, Martin C: Empirical antimicrobial therapy of septic shock patients: adequacy and impact on the outcome. Crit Care Med 2003, 31:462-467.

18. Ibrahim EH, Ward S, Sherman G, Schaiff R, Fraser VJ, Kollef MH: Experience with a clinical guideline for the treatment of ventilator-associated pneumonia. Crit Care Med 2001, 29:1109-1115.

19. Rello J, Gallego M, Mariscal D, Soñora R, Valles J: The value of routine microbial investigation in ventilator-associated pneumonia. Am J Respir Crit Care Med 1997, 156:196-200.

20. Kollef $\mathrm{MH}$ : Broad-spectrum antimicrobials and the treatment of serious bacterial infections: getting it right up front. Clin Infect Dis 2008, 47:S3-13.

21. Cainzos M: Review of the guidelines for complicated skin and soft tissue infections and intra-abdominal infections-are they applicable today? Clin Microbiol Infect 2008, 14(Suppl 6):9-18.

22. Levy MM, Fink MP, Marshall JC, Abraham E, Angus D, Cook D, Cohen J, Opal SM, Vincent JL, Ramsay G: 2001 SCCM/ESICM/ACCP/ATS/SIS International Sepsis Definitions Conference. Intensive Care Med 2003, 29:530-538.

23. Définitions des infections associées aux soins. [http://www.santejeunesse-sports.gouv.fr/IMG/pdf/rapport_vcourte.pdf]. 
24. Leone M, Perrin AS, Granier I, Visintini P, Blasco V, Antonini F, Albanese J, Martin C: A randomized trial of catheter change and short course of antibiotics for asymptomatic bacteriuria in catheterized ICU patients. Intensive Care Med 2007, 33:726-729.

25. Geissler A, Gerbeaux P, Granier I, Blanc P, Facon K, Durand-Gasselin J: Rational use of antibiotics in the intensive care unit: impact on microbial resistance and costs. Intensive Care Med 2003, 29:49-54

26. Mentzelopoulos SD, Pratikaki M, Platsouka E, Kraniotaki H, Zervakis D, Koutsoukou A, Nanas S, Paniara O, Roussos C, Giamarellos-Bourboulis E, Routsi C, Zakynthinos SG: Prolonged use of carbapenems and colistin predisposes to ventilator-associated pneumonia by pandrug-resistant Pseudomonas aeruginosa. Intensive Care Med 2007, 33:1524-1532.

27. Vincent JL, Rello J, Marshall J, Silva E, Anzueto A, Martin CD, Moreno R, Lipman J, Gomersall C, Sakr Y, Reinhart K: International study of the prevalence and outcomes of infection in intensive care units. JAMA 2009, 302:2323-2329.

28. Singh N, Rogers P, Atwood CW, Wagener MM, Yu VL: Short-course empiric antibiotic therapy for patients with pulmonary infiltrates in the intensive care unit. A proposed solution for indiscriminate antibiotic prescription. Am J Respir Crit Care Med 2000, 162:505-511.

doi:10.1186/cc9373

Cite this article as: Morel et al:: De-escalation as part of a global

strategy of empiric antibiotherapy management. A retrospective study in a medico-surgical intensive care unit. Critical Care 2010 14:R225.

\section{Submit your next manuscript to BioMed Central and take full advantage of:}

- Convenient online submission

- Thorough peer review

- No space constraints or color figure charges

- Immediate publication on acceptance

- Inclusion in PubMed, CAS, Scopus and Google Scholar

- Research which is freely available for redistribution

Submit your manuscript at www.biomedcentral.com/submit 